\title{
Análise dos Elementos que Formam a Ambiência de Inovação para seu Fomento nos Pequenos Negócios em Boa Vista-RR
}

\author{
Analysis of The Elements that form the Innovation Environment for their \\ Promotion in Small Businesses in Boa Vista-RR
}

\author{
Cleber Rotondo ${ }^{1}$ \\ Gelso Pedrosi Filho ${ }^{1}$ \\ Sebastião Rodrigo Ferreira ${ }^{1,2}$ \\ ${ }^{1}$ Universidade Federal de Roraima, Boa Vista, RR, Brasil \\ ${ }^{2}$ Universidade Federal do Sul da Bahia, Teixeira de Freitas, BA, Brasil.
}

\begin{abstract}
Resumo
Este estudo tem como objetivo avaliar a percepção dos atores do Sistema Local de Inovação (SLI) sobre a ambiência de inovação para pequenos negócios em Boa Vista, analisar as condições e barreiras existentes para a ambiência local e propor estratégias para o seu fortalecimento, baseadas no modelo Hélice Tríplice. Esta pesquisa é caracterizada como exploratória, qualitativa e de corte transversal. A coleta de dados foi realizada por meio de entrevista semiestruturada de representantes de entidades selecionadas do SLI. Os resultados apontaram, com exceção do Serviço Brasileiro de Apoio às Micros e Pequenas Empresas (SEBRAE), uma percepção de fraca atuação dos atores, afetando a credibilidade de todo o SLI. Constatou-se ainda uma articulação institucional satisfatória para trabalho estruturante, indicando que os atores estão conscientes da necessidade de atuação cumulativa e interativas.
\end{abstract}

Palavras-chave: Pequenos Negócios. Inovação. Tríplice Hélice. Sistema Local de Inovação.

\begin{abstract}
This study aims to assess the perception of the actors of the Local Innovation System (SLI) about the innovation environment for small businesses in Boa Vista, to analyze the existing conditions and barriers for the local environment and to propose strategies for its strengthening, based on the model Triple Helix. This research is characterized as exploratory, qualitative, and cross-sectional. Data collection was carried out through semi-structured interviews with representatives of selected SLI entities. The results showed, except for Serviço Brasileiro de Apoio às Micros e Pequenas Empresas (SEBRAE), a perception of weak performance by the actors, affecting the credibility of the entire SLI. It was also found a satisfactory institutional articulation for structuring work, indicating that the actors are aware of the need for cumulative and interactive performance.
\end{abstract}

Keywords: Small Business. Innovation. Triple Helix. Local Innovation System.

Área Tecnológica: Administração Pública e de Empresas. Ciências Contábeis e Turismo. 


\section{Introdução}

Setenta por cento da população ocupada no setor privado atua em pequenos negócios (AGÊNCIA SEBRAE DE NOTÍCIAS, 2017). São 50,6 milhões de pessoas que têm como fonte de receita os pequenos negócios, representando $27 \%$ do PIB nacional e gerando $54 \%$ da massa salarial. De acordo com pesquisa sobre inovação nos pequenos negócios realizada pelo Sebrae (2013), 75,1\% dos entrevistados realizaram algum tipo de inovação na empresa; 82,9\% afirmaram melhora na imagem; 86,7\% informaram melhora na satisfação; 32,9\% tiveram impacto de $16 \%$ a $30 \%$ no faturamento e $49,9 \%$ informaram impacto de $6 \%$ a $30 \%$ no lucro total. Tais indicadores demonstram que pequenos negócios contribuem na geração de emprego e distribuição de renda e que a inovação os fortalece.

Tratando-se de ambiente favorável à cooperação, o modelo de ambiência Tríplice Hélice, proposto por Etzkowitz e Leydesdorff (2000) apontam que as relações entre governo/universidade/empresa formam ambiente favorável à inovação tanto quanto mais perenes forem. Já o modelo Sistemas de Inovação enfatiza que a fruição da informação e da tecnologia entre atores da inovação continua fundamental e que com elementos, estruturas e funções bem definidas, ele pode ser auto organizado e de constante evolução.

Este estudo tem como objetivo analisar como os atores da ambiência de inovação se comportam para sua formação e fomento nos pequenos negócios de Boa Vista. A questão a responder é: como os atores do Sistema Local de Inovação avaliam a ambiência de inovação para os pequenos negócios em Boa Vista?

\subsection{Ambiência de Inovação}

O desenvolvimento da inovação acontece em contexto adequado para geração de conhecimento, ou seja, a ambiência propícia para inovação. Os contextos sociais interno e externo da organização promovem interações entre indivíduos e instituições e criam condições de aprendizagem tanto para o indivíduo quanto para a organização. Vicenti (2006) corrobora esse entendimento, ao afirmar que a ambiência de inovação acontece por contextos dentro ou fora da organização, provocando comportamentos nas pessoas para se enquadrarem na nova estrutura organizacional. Internamente à organização, são as formas utilizadas para despertar interesse em inovar nos colaboradores; já externamente, são mudanças no cenário que provocam na organização um novo alinhamento com o mercado em que está inserida (VAN DE VEN; ANGLE; POOLE, 2000).

A pesquisa: MOBIT (2010) trata das estratégias de inovação adotadas em sete países: Estados Unidos, França, Finlândia, Irlanda, Canadá, Reino Unido e Japão. Ela esclarece o papel da inovação e como é fomentada nesses países, em políticas e programas econômicos, analisando experiências internacionais bem-sucedidas que buscam a vanguarda do processo de inovação. 
De forma sintética, os pesquisadores enumeraram dez itens de maior relevância para inovação nos países pesquisados, apresentando norteamento para inovação no Brasil: o coração da estratégia de desenvolvimento é a inovação; inovação não é só tecnologia; inovação é conhecimento; o Estado é a chave para estimular, articular, regular e facilitar inovação; a empresa é alvo preferencial das políticas públicas; inovação e pesquisa de classe mundial; universidade mais aberta; esforço pelas pequenas empresas; mudanças no Estado e maturidade político-institucional. Da pesquisa MOBIT (2010), é possível extrair bases para construção de ecossistemas de inovação, em sentido amplo e não só tecnológico, fundamentado nas experiências desses países para fomentar inovação.

\subsection{Sistemas de Inovação}

Para enfrentar mercados cada vez mais dinâmicos e competitivos, cada país deve planejar, organizar e estruturar sua ambiência para ser favorável ao desenvolvimento de soluções inovadoras. Um ambiente propício estimula o surgimento de processos de inovação constantes, provocando crescimento da região e desenvolvimento social. Desses ambientes nacionais, surgiu o conceito de Sistema Nacional de Inovação (SNI). Um dos primeiros conceitos na literatura foi definido por Freeman (1995) e dizia que o SNI é formado por "[...] conjunto de instituições, atores e mecanismos em um país que contribuem para criação, avanço e difusão das inovações tecnológicas".

Para desenvolvimento da ambiência favorável à inovação, deve haver integração sinergética entre diferentes atores que formam o SNI, que contém os Sistemas Regionais de Inovação (SRIs). Nesses, os atores participam considerando cultura e economia locais. Onde há SRI, há políticas públicas para inovação, com propósito de fortalecer competitividade, de acordo com Cooke (1992).

\subsection{Hélice Tríplice}

Universidades, governo e empresas inseridas no SNI/SRI formam a Hélice Tríplice. Na literatura, há três estágios de desenvolvimento do modelo da Hélice Tríplice (Figura 1). No primeiro, chamado de Modelo Estático (ou estatista), o governo tem papel de controlador da academia e indústria, que são seus subordinados e têm relações direcionadas pelo governo. A inovação acontece pelo direcionamento dado pelo governo e não sendo fruto das interações universidade-empresa. O segundo é o Modelo Laissez-Faire, em que cabe à universidade papel de provedora de pessoas capacitadas e de pesquisa básica. Não há expectativa de empresas receberem muito suporte das universidades, tendo que encontrar conhecimentos úteis ao seu negócio em publicações. O terceiro é o propriamente denominado Modelo Hélice Tríplice. Ele forma uma espiral em que o fluxo do conhecimento vai das universidades para as empresas e vice-versa (WOLFFENBÜTEL, 2001). 
Figura 1 - Estágios de desenvolvimento da Hélice Tríplice

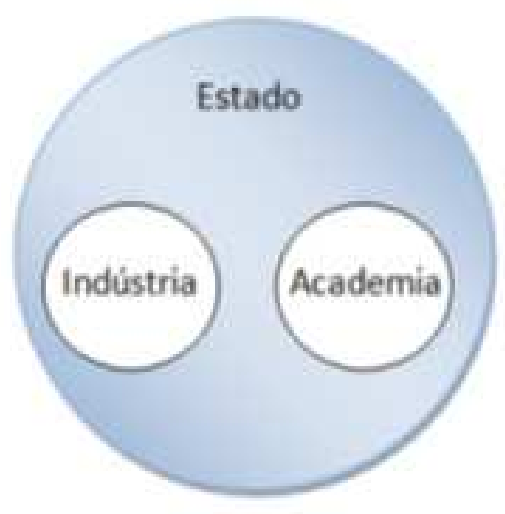

Modelo estático

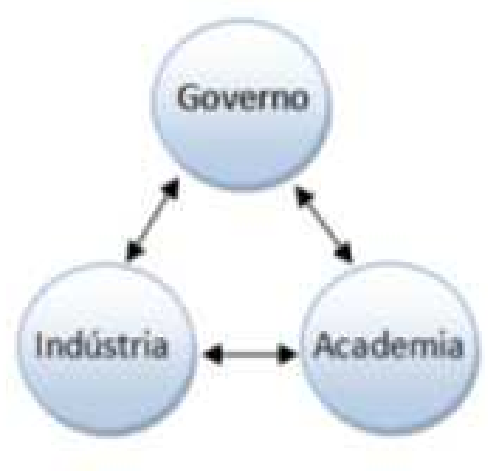

Modelo laissez-faire

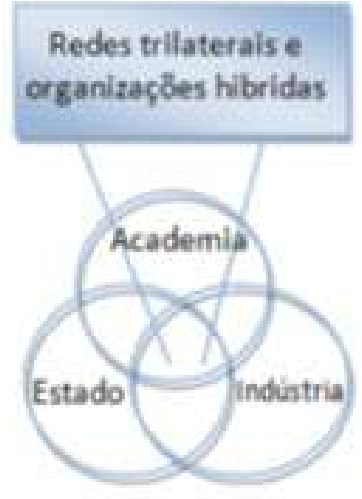

Modelo hélice triplice

Fonte: Gomes e Pereira (2015)

Segundo Etzkowitz e Zhou (2017), "[...] a Hélice Tríplice tornou-se modelo reconhecido internacionalmente, que está no âmago da disciplina emergente de estudos da inovação, é um guia de políticas e práticas nos âmbitos local, regional e multinacional".

Para a consolidação de uma Hélice Tríplice ideal, é necessário que haja uma sociedade civil vibrante (ETZKOWITZ; ZHOU, 2017), que pressione essas instituições em busca de soluções que atendam suas demandas com maior praticidade e assertividade. Nessa dinâmica de interações profundas, cabe à academia prover educação e tecnologia de ponta para produção de produtos inovadores. "O mundo acadêmico está entrando na era da universidade empreendedora" (ETZKOWITZ, 1983 apud ETZKOWITZ; ZHOU, 2017).

Com participação das universidades assumindo novo papel na sociedade, a Hélice Tríplice provoca dinâmica continua em prol do desenvolvimento, formando fundamentos para a existência de um eficaz ecossistema de inovação. De acordo com Etzkowitz e Zhou (2017), uma Hélice Tríplice deve ter como principais princípios: universidade empreendedora; empresas baseadas no conhecimento, resultantes das interações desenvolvidas na Hélice Tríplice; governo como moderador das relações e existência de instituições de capital de risco, seja do governo, corporação, universidade ou fundação.

\section{Metodologia}

Este estudo é caracterizado como exploratório, de natureza qualitativa e de corte transversal. É pesquisa exploratória, pois se buscou conhecer aprofundar o conhecimento sobre o assunto, tornando-o mais claro. Andrade (2002) destaca que pesquisa exploratória proporciona informações fundamentadas sobre o assunto, clareia tema e sua delimitação, facilita processo de definição dos objetivos e dá oportunidade para descoberta sobre novo enfoque. Para Gil (1999), pesquisa exploratória é indicada quando se quer ter visão geral sobre determinado fato. É de natureza qualitativa, pois "[...] podem descrever a complexidade de determinado problema, analisar interação de certas variáveis, compreender e classificar processos dinâmicos vividos por grupos sociais" (RICHARDSON, 1999). A abordagem qualitativa é capaz de destacar características, 
que por meio de abordagem quantitativa, não seriam observáveis. É de corte-transversal que analisa dados coletados aproximadamente ao longo de um mesmo período de tempo.

Foi realizada revisão bibliográfica qualitativa, levantando o estado da arte focada em ambiência de inovação: Sistema de Inovação e Tríplice Hélice. Para tanto, foram realizadas buscas por palavras-chave em plataformas como Scielo e Google Acadêmico para encontrar artigos científicos, dissertações e teses. Palavras-chave utilizadas: ambiência de inovação, sistemas de inovação, Tríplice Hélice, Sistema Nacional de Inovação, Sistemas Regionais de Inovação, Manual de OSLO, Pesquisa GEM de Empreendedorismo no Brasil, Instituto Brasileiro de Geografia e Estatística, IBGE, Pesquisa Industrial de Inovação Tecnológica, PINTEC, OCDE, FINEP, HSM Management e ABDI. Ainda nessa fase, foram realizadas buscas por autores, citados em referências bibliográficas de artigos, dissertações e teses. São eles: Schumpeter, Etzkowitz, Christensen, Vilella, Pimentel, Cardoso, Scherer, Carlomagno, Barbieri, Álvares, Bachmann, Destefani, Busch, Kline, Rosenberg, Van De Vem, Angle, Poole, Bessant, Pivitt, Lundvall, Freeman, Nelson, Cooke Wolffenbütel, Dossa, Segatto, Andrade, Gil e Richardson. Alguns desses autores não foram encontrados nas buscas nas plataformas, mas em livros.

Explorou-se dados primários que, segundo Mattar (2005), são coletados originariamente, não tendo sido trabalhados anteriormente, podendo ser sobre características demográficas, socioeconômicas e de estilo de vida, atitudes e opiniões, conscientização e conhecimento, motivações, comportamento passado e presente e intensões. São dados pesquisados especificamente para o trabalho em curso.

Foram realizadas entrevistas semiestruturadas com representantes das instituições (lideranças das áreas responsáveis por inovação) localizadas em Boa Vista, in loco ou por telefone. A população do estudo é constituída de 15 instituições representativas do segmento universidade e governo, por quatro empresas de pequeno porte selecionadas (Quadro 1). Os atores foram divididos em três grupos, de acordo com o modelo da Hélice Tríplice. No quadro abaixo, os atores da ambiência de inovação em Boa Vista são apresentados conforme o grupo em que foram enquadrados para realização desta pesquisa.

Quadro 1 - Atores da ambiência de inovação em Boa Vista

\begin{tabular}{|c|c|c|}
\hline U & G & E \\
Universidade Federal de Roraima (UFRR) & Prefeitura de Boa Vista/ & Daniel das Baterias \\
Universidade Estadual de Roraima (UERR) & Secretaria Ext. de & Osmar't Car \\
Instituto Federal de Educação & Inclusão Digital/CCTI & Personal Confecções \\
do Roraima (IFRR) & Instituto de Amparo à Ciência, & Roraima Adventures \\
Centro Universitário Estácio da Amazônia & Tecnologia e Inovação do & FIER \\
NIT UFRR & Estado de Roraima (IACTI/RR) & SEBRAE RR \\
NIT IFRR & Fundação Estadual do & SENAI RR \\
Instituto Euvaldo Lodi (IEL/RR) & Meio Ambiente e Recursos & EMBRAPA RR \\
& Hídricos (FEMARH) & Buriti Valley \\
\hline
\end{tabular}

Fonte: Elaborado pelos autores deste artigo

De uma amostra aleatória constituída por dois representantes da academia $(16,7) \%$, dois do governo $(16,7 \%)$ e por oito do setor empresarial $(66,6 \%)$, foram prestadas informações sobre o objetivo do estudo, sobre o anonimato e confidencialidade dos respondentes, e solicitado que assinassem o Termo de Consentimento Livre Esclarecido (TCLE). O questionário aplicado foi baseado e adaptado de Rodrigues (2013). Nas entrevistas semiestruturadas, o pesquisador se 
prepara elaborando lista de assuntos a serem abordados, possibilitando relativa flexibilidade nesse processo, podendo ser feitas perguntas não previstas. As entrevistas foram realizadas entre 17/12/2018 e 21/01/2019, com oito instituições e quatro empresários, em seguida, foram gravadas e feitas as transcrições das falas e interpretadas pelo pesquisador. Apoiando-se no trabalho de Rodrigues (2013), utilizou-se análise de conteúdo conforme aponta Bardin (1977), que a conceitua como:

[...] conjunto de técnicas de análise das comunicações, visando obter, por procedimentos sistemáticos e objetivos de descrição de conteúdo das mensagens, indicadores (quantitativos ou não) que permitam a inferência de conhecimentos relativos às condições de produção/recepção (variáveis inferidas) destas mensagens. (BARDIN, 1977, p. 42)

Como no questionário original, utilizou-se neste estudo a escala de desempenho de zero a dez, na qual pontuações de zero a seis classificam atuação fraca dos atores do SLI, entre sete e oito boa e entre nove e dez ótima.

\section{Resultados e Discussão}

A primeira questão abordou tema de suficiência de recursos destinados ao fomento do ambiente de inovação. Do total das respostas, 8,33\% concordam totalmente, 41,67\% concordam parcialmente, $16,67 \%$ discordam totalmente e $33,33 \%$ discordam parcialmente que os investimentos são suficientes. Por grupos componentes do sistema de inovação local, $100 \%$ dos grupos Universidade e Governo discordam parcialmente, já no grupo Empresa, predomina a opinião concorda parcialmente, com $62,50 \%$ das respostas, seguido de $25,50 \%$ discorda totalmente e $12,50 \%$ com a opinião de concorda totalmente. Com 62,50\%, a categoria Empresa apresenta o maior percentual de respondentes que concordam parcialmente que os recursos para fomentar o ambiente de inovação em Boa Vista são suficientes (Tabela 1). Constata-se que a percepção da suficiência parcial dos recursos predomina entre os atores.

Tabela 1 - Percentual de concordância com a suficiência de recursos para fomentar o ambiente de inovação em Boa Vista

\begin{tabular}{ccccc} 
& $\begin{array}{c}\mathbf{\%} \\
\text { Concorda }\end{array}$ & $\begin{array}{c}\mathbf{\%} \\
\text { Concorda }\end{array}$ & $\begin{array}{c}\mathbf{\%} \\
\text { Discorda }\end{array}$ & $\begin{array}{c}\mathbf{\%} \\
\text { Discorda }\end{array}$ \\
\cline { 2 - 5 } & Totalmente & Parcialmente & Totalmente & Parcialmente \\
\hline Universidade $(\mathrm{U})$ & 0,00 & 0,00 & 0,00 & 100,00 \\
Governo $(\mathrm{G})$ & 0,00 & 0,00 & 0,00 & 100,00 \\
Empresa (E) & 12,50 & 62,50 & 25,50 & 0,00 \\
Total & 8,33 & 41,67 & 16,67 & 33,33 \\
\hline
\end{tabular}

Fonte: Elaborada pelos autores deste artigo 
Um dos entrevistados ressaltou a importância da disponibilidade desses recursos:

[...] é fundamental para a criação de novos negócios no Brasil. Porém ainda existem poucas políticas e programas nacionais para que a universidade também se enxergue com a responsabilidade de geração de novos negócios, essas ações ainda são tímidas de uma forma geral e poderiam ajudar muito no fortalecimento de pequenos negócios nascidos a partir da vivência e aprendizados dos alunos. (ENTREVISTADO 1)

Outro entrevistado enfatizou preocupação com a participação do governo estadual para um maior investimento no fomento à ambiência de inovação:

Tem algum tipo de investimento, mas ele é pouco. Tem um movimento organizado no município, mas falta uma maior atuação do governo estadual, a sua participação é muito tímida. (ENTREVISTADO 12)

Outra deficiência percebida é a necessidade de melhoria das políticas públicas para a aplicação desses recursos:

Temos muita gente boa querendo fazer, mas a gente ainda peca muito em políticas públicas. (ENTREVISTADO 2)

A burocracia no setor público foi outra preocupação, manifestada, assim, por outro entrevistado:

Para trabalhar com órgãos públicos, tem que melhorar para dar suporte aos pequenos negócios, as secretarias não andam juntas, o suporte é ruim, a burocracia atrapalha. (ENTREVISTADO 3)

A preocupação com a qualidade do investimento, no sentido de como o recurso que é disponibilizado é aplicado, ficou evidenciada na manifestação de representante do grupo Empresa:

Acredito que mais importante do que o "quanto" é investido é o "como" esse investimento é aplicado. Universidades Públicas e Institutos Federais não serão promotores de inovação se não adotarem politicas de formação de pessoal, através do ensino, e de geração de conhecimentos e tecnologias, através da pesquisa, se essas atividades não estiverem em conexão com os reais interesses da sociedade na qual estão inseridas. (ENTREVISTADO 8)

De outro lado, verifica-se que o grupo Empresa considera que o recurso existente é bem aplicado para o fomento da inovação em Boa Vista, pois, quando foi atendido por essas instituições, principalmente a Universidade, obteve resultado favorável: "Funciona superbem!" (ENTREVISTADO 4) e "A intervenção das faculdades dentro das empresas disciplina o colaborador, traz entusiasmo" (ENTREVISTADO 5).

Reflexão interessante é a expressada por representante do grupo Governo, com relação aos recursos investidos e à postura dos empresários:

Se espera muito desses órgãos e se faz pouco. O empresário procrastina nessa dependência, fica aguardando esses órgãos e não desenvolve. A área de fomento de crédito é muito demorada e isso atrapalha o empresário. Junta de um lado o empresário que não age e, de outro, a demora da parte pública. (ENTREVISTADO 6) 
Assim, na percepção dos entrevistados, há investimentos para o fomento à inovação nos pequenos negócios em Boa Vista, mas que não são suficientes para suprir as necessidades. Há uma preocupação quanto à aplicação dos recursos existentes, embora o grupo de empresários tenha se mostrado satisfeito e há uma lentidão tanto dos entes públicos quanto do empresariado para investir em inovação.

Outro ponto abordado na entrevista foi o ambiente de interação entre empresas e universidades. No computo geral, essa questão está bem dividida, pois 50,00\% dos pesquisados consideram a interação satisfatória (ótimo ou bom) e os outros $50,00 \%$ consideram a interação insatisfatória (regular, ruim ou péssima). Analisando as respostas obtidas por grupo, verifica-se que 100,00\% dos grupos Universidade e Governo consideram a interação insatisfatória (Tabela 2). Por outro lado, o grupo empresa se dividiu igualmente nas avaliações satisfatória e insatisfatória.

Tabela 2 - Percentual da avaliação da interação universidade/empresa por grupo

\begin{tabular}{cccccc} 
& \% Ótimo & \% Bom & \% Regular & \% Ruim & \% Péssimo \\
Universidade (U) & 0,00 & 0,00 & 50,00 & 50,00 & 0,00 \\
Governo (G) & 0,00 & 0,00 & 100,00 & 0,00 & 0,00 \\
Empresa (E) & 37,50 & 37,50 & 12,50 & 12,50 & 0,00 \\
Total & 25,00 & 25,00 & 25,00 & 25,00 & 0,00 \\
\hline \hline
\end{tabular}

Fonte: Elaborada pelos autores deste artigo

Ficou demonstrada uma preocupação com burocracia das universidades que dificulta o relacionamento:

Atualmente temos uma legislação que dificulta e principalmente burocratiza o relacionamento da academia e do setor produtivo, principalmente quando se trata de universidades públicas. Esse clima inviabiliza boa parte dos relacionamentos que necessitam de criação de novos produtos em curto e médio prazo. Novas políticas estão sendo criadas e aperfeiçoadas e uma atualização sobre o papel da universidade para o desenvolvimento do país. (ENTREVISTADO 1)

Verificou-se que comunicação universidade/empresa precisa ser melhorada para a demanda das empresas chegar à universidade e a universidade comunicar para as empresas os projetos que desenvolve:

Temos um grande caminho a ser percorrido. Um passo importante foi dado para a formação desse ecossistema. Precisa trazer as pesquisas acadêmicas para dentro da empresa e vice-versa: levar a demanda das empresas para o meio acadêmico. Isso é fundamental, mas não está estruturado. Tem muita vontade, o povo acha que é importante, mas não está estruturado. A universidade desenvolve pesquisas muito boas, mas não chega ao empresariado, não sai da universidade. (ENTREVISTADO 7)

Também foi observada a necessidade de mudança de cultura das instituições com novo papel a ser desempenhado: 
Primeiramente esses atores necessitam se enxergar como agentes ativos no processo de inovação. Sem essa percepção dificilmente será possível construir o passo seguinte que é a atuação compartilhada direcionada para a promoção da inovação. O estabelecimento de alianças entre esses atores é primordial. Essa aliança significa identificar áreas de atuação comuns, onde que a atividade de uma instituição se complementa da atuação da outra, dentro de um ambiente de atuação sinérgica. (ENTREVISTADO 7)

O empresário entende que a inovação é tecnológica, portanto, é cara e complexa, tem que quebrar essa cultura. Tem que traduzir a linguagem técnica para o empresário, e a linguagem que o empresário entente é aquela que facilita, que torna mais barato e que gera mais lucro. (ENTREVISTADO 7)

Foi apontada a falta de ações efetivas para realização dessa interação: "Só o Programa Bolsa de Inovação Tecnológica de Roraima - BITERR faz essa aproximação. Então ainda falta bastante" (ENTREVISTADO 2).

Quando questionados sobre o que deve ser feito para que todos os atores que formam a ambiência de inovação tenham maior interação para gerar soluções para as necessidades locais, falou-se novamente da burocracia:

Elas têm que melhorar a burocracia entre elas mesmas. A burocracia é um dos maiores fatores para não se ter um processo que gere inovação estabelecido, pois a burocracia cria normas excessivas que dificultam a aproximação entre as instituições. (ENTREVISTADO3)

Também foi demonstrada preocupação com as políticas públicas:

Aperfeiçoamento das políticas públicas já existentes e a criação de um ambiente formal que una esses atores, com uma governança, análise de riscos e regulamentos bem definidos em uma organização jurídica destinada ao desenvolvimento científico e tecnológico da região. (ENTREVISTADO 1)

Foi ressaltada a falta de uma Fundação de Apoio a Pesquisa (FAP) em Roraima: "Primeira coisa é a criação de uma Fundação de Amparo à Pesquisa (FAP)." (ENTREVISTADO 2).

Nesta questão, novamente foi enfatizada a preocupação com a comunicação, criando espaços para a troca de informações entre os atores:

Devem visitar mais os microempresários para saber o que ele pensa e e para que ele possa ter um planejamento melhor para atender o microempresário. (ENTREVISTADO 8) Promover ações técnicas, visitar as empresas, ver como é na prática. (ENTREVISTADO 5) Promoção de eventos. Neles você consegue colocar eles no mesmo espaço e aí essa interação é estabelecida. Os eventos que existem não são para interação. (ENTREVISTADO 7)

Foi destacada a necessidade de governança ativa, com participação dos gestores das instituições, para que haja maior dinamismo e efetividade:

Em primeiro lugar, tem que ter uma governança estruturada, tem que ter a participação desses órgãos que têm o poder de decidir, contando com a participação efetiva das universidades, IFRR, mas com a participação desses órgãos públicos que têm o poder de definir políticas públicas. Essa participação é fundamental até para desdobrar as leis federais que já existem. (ENTREVISTADO 10) 
Interação das cabeças dos órgãos, pois quem participa dos eventos, que são técnicos, tem boa vontade e conhece, mas não tem poder de decisão. Os dirigentes têm que se inteirar da necessidade de inovação para o estado. (ENTREVISTADO 11)

Foram abordadas as ações prioritárias para ampliar a inovação nos pequenos negócios, solicitando aos entrevistados que indicassem propostas para melhoria. Houve proposta de conjunto de ações para ideação, capacitação, fomento financeiro e ambiente físico adequado e outra proposta para trabalhar conscientização dos empresários sobre o que é inovação:

Eventos que tragam novas ideias e inspirem a criação de negócios mais competitivos, capacitação de empresários, fomento financeiro para criação de novos negócios, ambientes de incubadora e aceleradoras, rodadas de negócios para investidores e ambientes para prototipação de produtos para aumento da competitividade. (ENTREVISTADO 1)

Primeiro trabalhar a conscientização dos empresários. O discurso é de mudança, mas quando se vai para a prática, muitos empresários acham que como sempre foi feito daquele jeito e deu certo, não precisa mudar. (ENTREVISTADO 2)

O grupo Empresa falou em aumento da concorrência, capacitação, mudança de mentalidade e atuação governamental:

Tentar buscar produtos de várias marcas para gerar concorrência e o cliente ter mais opções, comprar por preço melhor e gerar mais lucro, vendendo mais. E as empresas, para se manterem no mercado, têm que buscar um diferencial. (ENTREVISTADO 8)

$O$ Estado está mal-acostumado em pensar pequeno. Quem quer ter o conhecimento tem que procurar. Muita coisa amarra na questão burocrática. (ENTREVISTADO 3)

Precisa de ajuda governamental. Gostaria que tivessem palestras voltadas para a área. Ouvir as dificuldades dos empresários. Alguém enxergar as dificuldades e tentar resolve-las. (ENTREVISTADO 5)

O grupo Governo propôs criação de infraestrutura e atuação direta com empresários:

Desburocratização, incentivos a startups, criar espaços para esses empreendedores, internet que oscila muito. Construir esses espaços para eles trabalharem de uma forma mais adequada, eles têm um desenvolvimento muito maior, sem falar que eles juntos têm uma troca e um enriquecimento maior. (ENTREVISTADO 7)

O Sebrae tem feito um trabalho, mas os dados ficam nele mesmo. Quando a gente tem mais contato com os empresários, a gente tem condições de nortear as ações de inovação. Tem que ter uma visita direta aos pequenos negócios com ações mais abrangentes para um maior número de pessoas. (ENTREVISTADO 9)

Houve propostas tratando de comunicação com o empresário:

Temos que fazer um trabalho paralelo, a gente tem que trocar o pneu do carro com ele andando. A criação de um ecossistema tem uma participação fundamental, mas a gente tem que ir mais para dentro das empresas. A gente tem que mostrar ao empresário o que ele ganha. O empresário sabe que tem que inovar, mas ele não sabe o que ele ganha. Ele tem que ter uma certeza se vai ter uma estrutura para ampará-lo. Para ele ter garantido que não vai ficar sozinho. (ENTREVISTADO 10) 
Desmistificar que a inovação é cara, que é só para grandes empresas. Deixar bem claro o que é inovação; as pessoas acham que inovação é só uma nova ferramenta que a NASA inventou. Tem que desmistificar o que é inovação e ter exemplos práticos no mercado. Devia ter relatórios que apontassem mais isso. (ENTREVISTADO 11)

Trabalhando o questionário adaptado de Rodrigues (2013), a pesquisa abordou percepção dos atores sobre fatores que podem ser barreiras $(\mathrm{B})$, facilitadores $(\mathrm{F})$ ou não influenciadores (NI) na interação universidade/empresa (Tabela 3). Para isso, Rodrigues (2013) estabeleceu sete fatores, sendo quatro baseados em Segatto (1996) e três na realidade da Região Norte e programas do Ministério da Ciência, Tecnologia e Inovação (MCTI): diferença no nível de conhecimento empresário/universidade; burocracia universitária na transferência de tecnologia; fundos setoriais de apoio à pesquisa e duração do projeto e incubadoras de empresas; núcleo de inovação tecnológica e comunicação científica restrita ao meio acadêmico.

Tabela 3 - Fatores que influenciam no processo de interação universidade/empresa

\begin{tabular}{|c|c|c|c|c|c|c|c|c|c|c|c|c|}
\hline \multirow{2}{*}{ FATORES } & \multicolumn{3}{|c|}{ \% UNIVERSIDADE } & \multicolumn{3}{|c|}{ \% Governo } & \multicolumn{3}{|c|}{ \% EMPRESA } & \multicolumn{3}{|c|}{ \% Total Geral } \\
\hline & B & $\mathbf{F}$ & NI & B & $\mathbf{F}$ & NI & B & $\mathbf{F}$ & NI & B & $\mathbf{F}$ & NI \\
\hline $\begin{array}{c}\text { Diferença } \\
\text { no nível de } \\
\text { conhecimento } \\
\text { entre o } \\
\text { empresário/ } \\
\text { universidade }\end{array}$ & 50 & 50 & & 100 & & & 50 & 12,50 & 37,50 & 58,33 & 16,67 & 25,00 \\
\hline $\begin{array}{l}\text { Burocracia } \\
\text { Universitária na } \\
\text { transferência } \\
\text { de tecnologia }\end{array}$ & 100 & & & 100 & & & 75 & & 25 & 83,33 & & 16,67 \\
\hline $\begin{array}{l}\text { Comunicação } \\
\text { científica } \\
\text { restrita ao meio } \\
\text { acadêmico }\end{array}$ & 50 & & 50 & 50 & & 50 & 75 & 12,50 & 12,50 & 66,67 & 8,33 & 25,00 \\
\hline $\begin{array}{l}\text { Duração do } \\
\text { projeto }\end{array}$ & 50 & 50 & & 50 & & 50 & 87,50 & 12,50 & & 75,00 & 16,67 & 8,33 \\
\hline $\begin{array}{c}\text { Fundos } \\
\text { Setoriais } \\
\text { de apoio à } \\
\text { pesquisa }\end{array}$ & 100 & 0 & 0 & 100 & & & 50 & 25,00 & 25 & 66,67 & 16,67 & 16,67 \\
\hline $\begin{array}{l}\text { Incubadora } \\
\text { de Empresa }\end{array}$ & 0 & 100 & 0 & 100 & & & 37,50 & 37,50 & 25,00 & 41,67 & 41,67 & 16,67 \\
\hline $\begin{array}{l}\text { Núcleo de } \\
\text { Inovaçãa } \\
\text { Tecnológica }\end{array}$ & 0 & 100 & 0 & 100 & & & 37,50 & 37,50 & 25 & 41,67 & 41,67 & 16,67 \\
\hline
\end{tabular}

Fonte: Elaborada pelos autores deste artigo

No tocante à opinião dos entrevistados, verifica-se no fator diferença no nível de conhecimento entre o empresário/universidade a predominância do entendimento de que é barreira, com 58,33\%; seguido do entendimento como não influenciador, com 25,00\% e 16,67\% consideram 
como facilitador. Para a região, que apresenta um perfil empresarial básico em tecnologia, esse fator interfere significativamente na interação universidade/empresa. O fator burocracia universitária na transferência de tecnologia foi considerado barreira por 83,33\% dos entrevistados, enquanto $16,67 \%$ o consideram não influenciador. Questões como propriedade intelectual e exigência de sigilo na divulgação de resultados compõem o fator. A comunicação científica restrita ao meio acadêmico é vista como barreira para $66,67 \%$ dos entrevistados, seguida por não influenciador por $25 \%$, tendo $8,83 \%$ como facilitador. A duração do projeto é considerada barreira para $75 \%$ dos entrevistados, $16.67 \%$ como facilitador e $8,33 \%$ não influenciador.

Estudo de Costa (2009) constatou que em projetos de pesquisa que envolvem interação universidade/empresa, mesmo havendo reciprocidade na parceria, sua execução é complexa, pois os objetivos envolvidos são diferentes:

A transferência de tecnologia da pesquisa para a empresa é um processo complexo por se tratar de uma relação de reciprocidade entre parceiros. Diferente da relação de troca entre duas empresas, o objetivo da primeira não é a produção industrial imediata de um novo produto, mas o desenvolvimento de um novo conhecimento que só se realiza através da realização conjunta de atividades de pesquisa. (MACULAN apud COSTA, 2009, p. 44)

Os próximos três fatores foram pesquisados com relação ao acesso. $\mathrm{O}$ acesso aos fundos setoriais de apoio à pesquisa é visto por 75,00\% dos entrevistados como barreira, 16,67\% consideraram facilitador e 8,33\% como não influenciador. Quanto ao acesso à incubadora de empresas, a opinião ficou bastante dividida, com $41,67 \%$ considerando barreira e o mesmo percentual considerando facilitador, enquanto $16,67 \%$ consideraram não influenciador. Destacam-se os grupos universidade, com $100 \%$ como facilitador e governo, em que o mesmo percentual considerou barreira. Isso em razão de a única incubadora de Boa Vista ser gerida pela UFRR, mas os entrevistados do governo a entendem como desativada. O acesso aos NITs também é visto de forma dividida, com percentuais para barreira, influenciador e não influenciador em 41,67\%, 41,67\% e 16,67\%, respectivamente. Os percentuais das respostas repetem a percepção encontrada para as incubadoras, em razão de os NITs serem considerados muito voltados para universidades, com pouca atuação para empresas, conforme opiniões apresentadas em questões anteriores.

A pesquisa também abordou a atuação de atores do SLI para inovação nos pequenos negócios (Tabela 4). Alguns grupos não somam $100 \%$ na avaliação, em razão de entrevistados terem respondido que não conhecem o ator avaliado. Quatro instituições tiveram percentuais de avaliação concentrados na classificação de atuação fraca, duas com atuação boa e duas com atuação ótima. Essa concentração indica baixa credibilidade na atuação para fomento à inovação, dificultando a formação de ambiência favorável à inovação em Boa Vista, pois o atendimento às demandas e a geração de soluções acontecem em menor escala, atingindo a credibilidade de todo o SLI. Mesmo assim, destaca-se a credibilidade do Sebrae, com avaliação ótima de $75 \%$ dos entrevistados, indicando que há atuação bem realizada para fomento à inovação e que a baixa credibilidade pode ser revertida. 
Tabela 4 - Atuação para a Inovação nos pequenos negócios

\begin{tabular}{|c|c|c|c|c|c|c|c|c|c|c|c|c|}
\hline \multirow{2}{*}{ Атов } & \multicolumn{3}{|c|}{ \% UNIVERSIDADE (U) } & \multicolumn{3}{|c|}{ \% Governo (G) } & \multicolumn{3}{|c|}{ \% EMPRESA (E) } & \multicolumn{3}{|c|}{ \% Total Geral } \\
\hline & $\mathbf{F}$ & B & O & $\mathbf{F}$ & B & $\mathbf{O}$ & $\mathbf{F}$ & B & $\mathbf{O}$ & $\mathbf{F}$ & B & $\mathbf{O}$ \\
\hline NITs & 50 & 50 & & 100 & & & 75,00 & 25,00 & & 66,67 & 16,67 & \\
\hline $\begin{array}{l}\text { Incubadora } \\
\text { de Empresa }\end{array}$ & 50 & & 50 & 50 & & 50 & 62,50 & 25,00 & & 58,33 & 16,67 & 16,67 \\
\hline FAP & 50 & & 50 & 100 & & & 62,50 & 25,00 & & 66,67 & 16,67 & 8,33 \\
\hline UFRR & 50 & 50 & & 50 & 50 & & 75,00 & 12,50 & 12,50 & 66,67 & 25,00 & 8,33 \\
\hline $\begin{array}{c}\text { Secretaria } \\
\text { Estadual de } \\
\text { CT\&Inovação }\end{array}$ & 50 & & 50 & 50 & 50 & & 62,50 & & 12,50 & 58,33 & 8,33 & 16,67 \\
\hline FIER & & 50 & 50 & & & 50 & 37,50 & 37,50 & 12,50 & 16,67 & 33,33 & 25,00 \\
\hline SEBRAE & & & 100 & & 50 & 50 & 12,50 & 12,50 & 62,50 & 8,33 & 16,67 & 75,00 \\
\hline SENAI & & 100 & & & 50 & 50 & 37,50 & & 37,50 & 16,67 & 25,00 & 41,67 \\
\hline INCT & & 100 & & & & & 25,00 & & & 8,33 & 16,67 & \\
\hline UERR & & 100 & & & 100 & & 25,00 & 12,50 & & 25,00 & 41,67 & \\
\hline
\end{tabular}

Fonte: Elaborada pelos autores deste artigo

Em seguida foi abordada a disposição para elaborar projetos conjuntos e diálogos estratégicos (Tabela 5). Cinco atores apresentaram concentração de avaliação ótima e três foram mais avaliados como boa, indicando que há articulação institucional satisfatória para trabalho coletivo e estruturante. Os atores da ambiência de inovação em Boa Vista estão cientes da necessidade de atuação cumulativa e interativa e dispostos a isso, o que contribui favoravelmente para o desenvolvimento do SLI.

Tabela 5 - Disposição para elaborar projetos conjuntos e para realizar diálogos estratégicos

\begin{tabular}{|c|c|c|c|c|c|c|c|c|c|c|c|c|}
\hline \multirow{2}{*}{ AтоR } & \multicolumn{3}{|c|}{ \% UNIVERSIDADE (U) } & \multicolumn{3}{|c|}{ \% Governo (G) } & \multicolumn{3}{|c|}{ \% EMPRESA (E) } & \multicolumn{3}{|c|}{ \% Total Geral } \\
\hline & $\mathbf{F}$ & B & $\mathbf{O}$ & $\mathbf{F}$ & B & $\mathbf{O}$ & $\mathbf{F}$ & B & $\mathbf{O}$ & $\mathbf{F}$ & B & O \\
\hline NITs & & 50 & 50 & 100 & & & 25,00 & 25,00 & 12,50 & 33,33 & 16,67 & 16,67 \\
\hline $\begin{array}{l}\text { Incubadora } \\
\text { de Empresa }\end{array}$ & & 50 & 50 & 50 & 50 & & 25,00 & 50,00 & 12,50 & 25,00 & 50,00 & 16,67 \\
\hline UFRR & & 50 & 50 & 50 & & 50 & 12,50 & 37,50 & 37,50 & 25,00 & 33,33 & 41,67 \\
\hline FIER & & 100 & & & & 50 & 12,50 & 12,50 & 50,00 & & 25,00 & 41,67 \\
\hline SEBRAE & & 50 & 50 & 50 & & 50 & & & 100,00 & & 16,67 & 66,67 \\
\hline SENAI & 50,00 & 50 & & 50 & & 50 & 25,00 & 12,50 & 37,50 & 25,00 & 16,67 & 33,33 \\
\hline UERR & 50,00 & 50 & & 100 & & & 50,00 & & 25,00 & 58,33 & 8,33 & 16,67 \\
\hline IFRR & & 50 & 50 & 50 & & 50 & 25,00 & & 75,00 & 25,00 & 8,33 & 66,67 \\
\hline
\end{tabular}

Fonte: Elaborada pelos autores deste artigo 


\section{Considerações Finais}

Os pequenos negócios têm expressiva participação na geração de empregos, contribuindo com mais de $50 \%$ das vagas formais existentes. Com participação tão marcante na economia, é necessário que a ambiência de inovação busque atender às suas necessidades. Tratando-se de ambiente favorável à cooperação, a Hélice Tríplice é um modelo de ambiência de inovação que argumenta que as relações governo/universidade/empresa formam ambiente propício à inovação tanto quanto essas mais perenes forem. A existência de um SLI é capaz de provocar essa ambiência. Em Roraima, o incentivo ao empreendedorismo e ao crescimento da iniciativa privada é fundamental para seu desenvolvimento.

Os atores locais concordam parcialmente que há recursos suficientes destinados ao fomento do ambiente de inovação para os pequenos negócios em Boa Vista, embora haja críticas quanto a políticas e programas nacionais para que a universidade desenvolva tecnologia para geração de novos negócios. Verificou-se que existe um movimento organizado para fomento à inovação em Boa Vista, mas que se ressente de atuação mais forte do governo estadual. A universidade entende que faltam políticas públicas mais bem estruturadas para o desenvolvimento da inovação. A falta de uma FAP no estado, único da federação em que não existe esse ator, evidencia a tímida atuação do governo estadual para fomento à inovação.

A pesquisa verificou que burocracia excessiva é um entrave para o SLI, pois provoca morosidade na organização e na operacionalização das ações, além de dificultar realização de ações dos atores em parceria. Evidenciou-se preocupação com aplicação dos recursos disponibilizados, para que haja geração de conhecimentos e tecnologias que tenham conexão com reais interesses da sociedade local, demonstrando que o processo de comunicação precisa ser aprimorado.

A cultura local para a inovação ainda não está consolidada. As universidades não têm foco no desenvolvimento de ciência aplicada para a geração de inovação e os empresários de pequenos negócios veem a inovação como algo caro e distante da realidade. É preciso priorizar atividades para formar cultura de inovação nas universidades e pequenos negócios. Na pesquisa foram analisados fatores que podem influenciar na formação da ambiência de inovação, constatando que cinco são barreiras, o que revela a percepção de grande carência em Boa Vista, indicando que este ambiente precisa ser fortalecido. Também se constatou baixa credibilidade quanto à atuação para inovação, mas há disponibilidade para interagir no fomento à inovação.

Em resposta à questão norteadora da pesquisa: como os atores do SLI avaliam ambiência de inovação para pequenos negócios em Boa Vista-RR? Constatou-se que os recursos para formação da ambiência de inovação são avaliados como parcialmente suficientes, existe movimento favorável para essa ambiência, mas a cultura local para a inovação precisa ser fortalecida, sendo necessário nivelar conhecimento entre empresários/universidade, reduzir burocracia e melhorar comunicação. A falta de uma FAP também é percebida como atraso no amadurecimento da ambiência de inovação. Como medidas de apoio e fomento à ambiência de inovação para os pequenos negócios em Boa Vista, propõe-se: implantação de uma Fundação de Amparo à Pesquisa; trabalhar cultura local para a inovação; desburocratizar instituições públicas e melhorar canais de comunicação entre atores do SLI. 


\section{Referências}

AGÊNCIA SEBRAE DE NOTÍCIAS. Pequenos negócios abrigam 70\% dos ocupados do setor privado. [2017]. Disponível em: http://www.agenciasebrae.com.br/ Acesso em: 10 nov. 2017.

ANDRADE, M. M. Como Preparar Trabalhos para Cursos de Pós-Graduação: noções práticas. 5. ed. São Paulo: Atlas, 2002.

BACHMANN, D. L.; DESTEFANI, J. H. Metodologia para estimar o grau de inovação nas MPE: cultura do empreendedorismo e inovação. Curitiba: [s.n.], 2008. Disponível em: http://bachmann. com.br/website/.../ArtigoGrauInovacaonasMPE.pdf. Acesso em: 15 dez. 2018.

BARDIN, L. Análise de Conteúdo. Trad. Luís Antero Reto e Augusto Pinheiro. 1. ed. São Paulo: Martins Fontes, 1977.

COOKE, P. Regional Innovation Systems: Competitive Regulation in The New Europe. Geoforum, [s.l.], v. 23, p. 365-382, 1992.

COSTA, E. O. Modelo de relação universidade-empresa baseada em comunidades de prática: espaço interativo (EI). 2009. 116 p. Dissertação (Mestrado em Engenharia e Gestão do Conhecimento) - Centro Tecnológico, Universidade Federal de Santa Catarina, Florianópolis, 2009.

ETZKOWITZ, H.; LEYDESDORFF, L. The Dynamics of Innovation: From National Systems and 'Mode 2' to a Triple Helix of University-Industry-Government Relations. Research Policy, [s.l.], v. 29, p. 109-123, 2000.

ETZKOWITZ, H.; ZHOU, C. Hélice Tríplice: inovação e empreendedorismo universidade-indústriagoverno. Estudos Avançados, [s.l.], v. 31, p. 23-48, 2017.

FREEMAN, C. The 'National System of Innovation' in historical perspective. Cambridge Journal of Economics, [s.l.], v. 19, p. 5-24, 1995.

GIL, A. C. Métodos e Técnicas de Pesquisa Social. 5. ed. São Paulo: Atlas, 1999.

GOMES, M. A. S.; PEREIRA, F. E. C. Hélice Tríplice: um ensaio teórico sobre a relação universidade-empresa-governo em busca da inovação. International Journal of Knowledge Engineering and Management, [s.l.], v. 4, n. 8, p. 136-155, mar.-jun. 2015.

HSM MANAGEMENT. Incremental ou Radical? Mar.-abr., 2005.

IBGE - INSTITUTO BRASILEIRO DE GEOGRAFIA E ESTATÍSTICA. Pesquisa de Inovação: PINTEC. Rio de Janeiro: IBGE, 2016.

LUNDVALL, B. A. National innovation systems of innovation. London: Pinter, 1992

MATTAR, F. N. Pesquisa de marketing: metodologia, planejamento. 6. ed. São Paulo: Atlas, 2005.

MOBIT. Pesquisa Inovação: estratégia de sete países. Organizadores Glauco Arbix... [et al.].

Brasília, DF. il. 2010 (Cadernos da indústria ABDI; XV). Disponível em: http://www.iea.usp.br/ pesquisa/grupos/observatorio-inovacao-competitividade/publicacoes/online/inovacao-estrategias-desete-paises. Acesso em: 2 dez. 2018.

OCDE; EUROSTAT; FINEP. Manual de Oslo: diretrizes para coleta e interpretação de dados sobre inovação. 3. ed. Rio de Janeiro: FINEP, 2005. Disponível em: www.finep.gov.br. Acesso em: 26 maio 2017. 
RICHARDSON, R. J. Pesquisa Social: Métodos e Técnicas. 3. ed. São Paulo: Atlas, 1999.

RODRIGUES, E. D. Análise da Ambiência Institucional de Ciência, Tecnologia e Inovação (CT\&I) na Amazônia Legal. 2013. 136 p. Dissertação (Mestrado em Desenvolvimento Regional) Universidade Federal do Tocantins, Palmas, 2013.

SEGATTO, A. Análise do Processo de Cooperação Tecnológica Universidade-Empresa: um estudo exploratório. 1996. 175 p. Dissertação (Mestrado em Administração) - Universidade de São Paulo, São Paulo,1996.

SEBRAE - SERVIÇO BRASILEIRO DE APOIO ÀS MICROS E PEQUENAS EMPRESAS. Inovação nos pequenos negócios. Disponível em: https://bis.sebrae.com.br/bis/conteudoPublicacao.zhtml. Acesso em: 10 de novembro de 2017

SCHERER, F. O.; CARLOMAGNO, M. S. Gestão da inovação na prática. São Paulo: Atlas, 2009.

SCHUMPETER, J. A. A teoria do desenvolvimento econômico. São Paulo: Abril, 1982.

VAN DE VEN, A. H.; ANGLE, H. L. An introduction to the Minnesota Innovation Research Program. In: VAN DE VEN, A. H.; ANGLE, H. L. Research on the Management of Innovation: the Minnesota Studies. New York: Ballinger; Harper \& Row, 2000. p. 3-30.

VICENTI, T. Ambiente de Inovação nas Empresas de Software de Blumenau. 2006. 202 p. Dissertação (Mestrado: Programa de Pós-Graduação em Administração) - Universidade Regional de Blumenau, Blumenau, 2006.

\section{WOLFFENBÜTTEL, A. P. Avaliação do Processo de Interação Universidade-Empresa em} Incubadoras Universitárias de Empresas: um Estudo de Caso na Incubadora de Empresas de Base Tecnológica da UNISINOS. 2001, 162 p. Dissertação (Mestrado em Administração) Universidade Federal do Rio Grande do Sul, Porto Alegre, 2001.

\section{Sobre os Autores}

\section{Cleber Rotondo}

E-mail: cleber.rotondo@rr.sebrae.com.br

Mestre em Propriedade Intelectual e Transferência de Tecnologia para a Inovação pela Universidade Federal de Roraima em 2019.

Endereço profissional: Rua Governador Aquilino Mota Duarte, n. 1.771, São Francisco, Boa Vista, RR. CEP: 69305-095.

\section{Gelso Pedrosi Filho}

E-mail: gelso.pedrosifilho@ufrr.br

Doutorado em Gestão de Empresas pela Universidade de Coimbra, UC, Portugal em 2012.

Endereço profissional: Av. Cap. Ene Garcês, n. 2.413, Aeroporto, Boa Vista, RR. CEP: 69310-000.

\section{Sebastião Rodrigo Ferreira}

E-mail: sebastiao.rodrigo@ufsb.edu.br

Doutor em Parasitologia pela Universidade Federal de Minas Gerais em 2015.

Endereço profissional: Praça Joana Angélica, n. 250, São José, Teixeira de Freitas, BA. CEP: 45988-058. 